\title{
OBSERVATIONS ON THE PATH OF FARADIC SENSIBILITY*
}

\author{
G. P. GRABFIELD, M.D. \\ ANN ARBOR, MICH.
}

The present study deals with the afferent path of faradic stimuli. The evidence here presented has been largely gathered from a study of cases presenting certain neurologic lesions or psychiatric conditions, and suggests that faradic stimuli of liminal value probably follow the path of the thermal fibers, while markedly supraliminal stimuli may use other paths. As was to be expected, the postrolandic cortex is in all likelihood the arrival platform for these impulses.

METHOD USED IN MAKING TESTS

The method used eliminates subjective influences both from the patient and operator. Heretofore, quantitative sensory tests have been of only relative accuracy and most unsatisfactory. Even the ordinary qualitative sensory tests are not perfectly objective. There have been three chief objections to previous attempts at quantitating tests of sensation: First, lack of absolute accuracy, i. e., the difficulty of reproducing exactly a stimulus of given intensity at will; second, lack of objectivity, and third, the ease of deception by the patient. These three factors of error have been eliminated by employing the method devised by Martin ${ }^{1}$ for the measurement of shocks delivered by the secondary coil of an inductorium in absolute units which he called beta units. By the use of this method any given stimulus can be reproduced exactly. The subject has no means of knowing when the stimulus is applied, as he sits in another room, and no noise warns him of the application of the stimulus. The operator has an absolute check on the accuracy of the patient's replies, by stimulating the patient with

*Study No. 6 in a series entitled "Variations in the Sensory Threshold for Faradic Stimulation in Psychopathic Subjects."

* This work was done during the tenure of an internship at the Psychopathic Hospital, Boston.

1. Martin, E. G.: A Quantitative Study of Faradic Stimulation. I. The Variable Factors Involved, Am. J. Physiol. 22:61, 1908. Ibid.: II. The Calibration of the Inductorium for Break Shocks, ibid. 22:118, 1908; ibid.: III. The Measurement of Make Shocks, ibid. 24:269, 1909; ibid.: IV. The Make and Break Key, ibid. 26:181, 1910; ibid.: V. The Influence of Tissue Resistance and of Kathode Surface on Stimulating Effectiveness, ibid. 27:226, 1910; ibid.: VI. The Comparison of One Inductorium with Another, ibid. 28:49, 1911; ibid. : Measurement of Induction Shocks, New. York, 1913; ibid.: On the Validity of Inductorium Calibrations, ibid. 36:223, 1915. 
shocks of varying intensity, any one of which may be repeated as often as is deemed desirable. A brief description of the method as employed by us follows.

The measurement of shoeks delivered by the secondary coil of an inductorium by this method depends on the fact that with a given current passing through the primary the shock delivered by the secondary coil (on making or breaking the primary circuit) depends on the proximity of the secondary to the primary coil in any given plane. The exact relation between shock delivered and intercoil distance varies with the inductorium used. This must be calibrated for both make and break shocks. ${ }^{2}$ Throughout this work only break shocks were used. These were delivered by the "Make-and-Break Key," ${ }^{3}$ the advantage of which lies in the fact that it allows a uniform make or break as the case may be, and enables one to short-circuit the one or the other.

The shocks from the secondary were delivered to the patient by electrodes of the mercury-calomel-salt-solution type described by Martin, Porter and Nice ${ }^{4}$ as the most advantageous for work with human subjects. They also found that abrasions of the fingers used in the test (or the use of platinum points thrust under the skin as electrodes) lowered the average human threshold markedly. This is a practical point of some importance in dealing with maniacal patients who often sustain slight injuries. These electrodes consist of two tubes about 5 inches long and of a diameter to admit the fingers comfortably. The wires from the secondary coil are led to the bottom of these tubes (one into each tube) over the top of the tube. The insulation of the wires is stripped for a distance of 1 or $2 \mathrm{~cm}$. from their ends, which rest on the bottom of the tubes. Around the ends of these wires is a layer of mercury, over which lies a layer of calomel paste to a depth of $2 \mathrm{~cm}$. The rest of the tube is filled with 15 per cent. salt solution.

The patient dips the middle and index fingers of his left hand into the electrodes and is instructed to press a telegraph key whenever he feels a shock. The operator starts with the secondary coil in such a position that it will deliver a subliminal shock, and gradually approaches it to the primary, breaking the current at short irregular intervals. Finally, the patient signals, indicating that he has felt the shock. This

2. Martin, E. G.: Am. J. Physiol. 22:118, 1908; ibid. 24:269, 1909; ibid. 28:49, 1911 ; ibid. 36:223, 1915.

3. Martin, E. G.: Am. J. Physiol. 26:181, 1910.

4. Martin, E. G.; Porter, E. L., and Nice, L. B.: Sensory Threshold for Faradic Stimulation in Man, Psychol Rev. 20:194, 1913. 
point and its environs are tried and retried until the point farthest from the primary is found where the patient feels practically every shock. This can be found within $2 \mathrm{~mm}$. as measured on a scale which has as its zero the point where the secondary lies over the primary and encloses it. This procedure is repeated three times with ten, twenty and thirty thousand ohms, respectively, introduced into the primary circuit. From this it is evident that deception on the part of the patient is impossible. The entire procedure consumes about six minutes, on the average, though perseverance will frequently procure a reading from a subject who at first seems to offer no cooperation whatever. The resistance of the coil used in this work is 2,900 ohms. In work of the highest accuracy it is necessary to determine the resistance of the patient's skin by the somewhat tedious Kohlrausch method. This resistance has been found to be very constant, however, and in our work we felt that it was better not to determine the resistance in each case, on account of the time necessary for the procedure and the restiveness of certain patients. We have taken the skin resistance to be 2,100 ohms, the average of a large number of observations, three quarters of which fall within $300 \mathrm{ohms}$ of this figure. This omission introduces only a small percentage error, especially in dealing with high threshold values. Thus, in the secondary circuit there is the resistance of the secondary coil $(2,900 \mathrm{ohms})$ plus the resistance of the patient's skin $(2,100 \mathrm{ohms})$ or $5,000 \mathrm{ohms}$. Our four readings of the position of the secondary coil are made with a total of five, fifteen, twenty-five and thirty-five thousand ohms' resistance in the secondary circuit. From these resistances, the value of the current passing through the primary coil, and the position of the secondary coil, the value of the threshold shock is calculated by certain formulae developed by Martin ${ }^{5}$ as modified by Wilbur. ${ }^{6}$ The primary current used throughout this work (except in the cases of syringomyelia) was 0.3 ampere.

Throughout this work the results have been expressed in the num. ber of beta units required to cause sensation. One beta unit is the average amount of faradic shock necessary to cause a minimal contraction of a frog's gastrocnemius stimulated through the sciatic nerve in the classic nerve-muscle preparation."

It is to be emphasized that in interpreting the results here presented, the higher the figure given (in beta units) the less sensitive is the subject.

5. Martin, E. G.: Measurement of Shocks, New York, 1913.

6. Martin, E. G.; Bigelow, G. H., and Wilbur, G. B.: Variations in the Sensory Threshold for Faradic Stimulation in Normal Human Subjects. II. The Nocturnal Variation, Am. J. Physiol. 33:415, 1914. 


\section{PREVIOUS WORK}

Since the introduction of this method in 1908, considerable work has been done on the variations of this threshold in normal and psychopathic human subjects and in the experimental animal under various conditions. Martin, Porter and $\mathrm{Nice}^{4}$ found that there was a practically constant threshold value for a normal human subject, tested as described above. As a result of introspective observations, they suggested that this form of sensation was allied to muscle or joint sensibility. Continuing the work on normal human subjects certain evidence was accumulated to show that this method might be used as an index of the functional condition of the central nervous system. It was found that this threshold had a definite diurnal variation ${ }^{7}$ which corresponds closely with the curve of ergographic output as reported by Lombard, ${ }^{8}$ and with the diurnal variation of the reaction time as recorded by Ostanikow and Gran. ${ }^{\theta}$ The lack of closer correspondence with the latter curve may be ascribed to the fact that these authors made only four observations in the course of a day as compared with hourly observations in the study on this threshold. Martin, Bigelow and Wilbur ${ }^{6}$ worked out a nocturnal rhythm which was found to agree closely with the depth of sleep as measured by Mönninghoff and Piesbergen, ${ }^{10}$ the periods of low irritability coinciding with those of greatest sleep intensity. It was further found in this study that the second low point in irritability corresponds with the point of lowest body temperature. ${ }^{11}$ The influence of general fatigue on this threshold is of some importance in the use of the threshold value clinically for the examination of ambulatory cases. In this study ${ }^{12}$ it was found that men under a somewhat pressing but regular routine showed a curve of decreasing irritability as the week wore on. This curve was

7. Grabfield, G. P., and Martin, E. G.: Variations in the Sensory Threshold for Faradic Stimulation in Normal Human Subjects. I, The Diurnal Rhythm, Am. J. Physiol. 31:300, 1913.

8. Lombard, W. P.: Some of the Influences which Affect the Power of Voluntary Muscular Contractions, J. Physiol. 13:25, 1892.

9. Ostanikow, P., and Gran, M.: Ueber die Geschwindigskeitsveränderungen der psychischen Processe zu verschiedenen Tageszeiten, Neurol. Centralbl. 12:290, 1893.

10. Mönninghoff, $O$, and Piesbergen, F.: Messungen über die Tife des Schlates, Ztschr. f. Biol. 19:114, 1883.

11. Jürgenson and Liebermeister: Handbuch der Pathologie und Therapie des Fiebers, Leipzig, 1875; quoted by Pembrey in Schäfer: Textbook of Physiology, Edinburgh and London 1: 1890. Jürgenson, T.: Die Körperwärme des Gesunden Menschen, Leipzig, 1813.

12. Martin, E. G. ; Withington, P. R., and Putnam, Jr., J. J.: Variation in the Sensory Threshold for Faradic Stimulation in Normal Human Subjects. III. The Influence of General Fatigue, Am. J. Physiol. 34:97, 1914. 
obtained by testing the men at the same time each day. With the intervention of Sunday and relief from their routine, the irritability increased to the point where it had begun the week before. Martin, Paul and Welles ${ }^{13}$ found the threshold of the winking reflex in man to be about twice that of the sensory threshold and concluded that "the value of the sensory threshold depends on the state of the higher nervous centers, and that the threshold may justly be used, therefore, as an indicator of such nervous state."

The indication that "synaptic resistance" probably has an effect on this threshold suggested certain animal experiments which showed that in the spinal cat ${ }^{14}$ the threshold for the radial nerve-muscle preparation is almost exactly half as high as that for the flexion reflex obtained by stimulating the tibial nerve. In a further study of the variations in the threshold of the reflex $\operatorname{arc}^{15}$ it was found that an excess of carbon dioxid raised the limen of the flexion reflex in the spinal cat to the point of its total disappearance, and that this effect varied with the percentage of oxygen present. This suggests that a study of neuropathic cyanosis may permit of correlation with this observation.

Finally, a group of experimental studies ${ }^{18}$ on the limen of the vasomotor center showed that the intensity of the stimulus to the nervous system may make a difference in the responses to two stimuli varying in strength and not in kind. These studies also showed that the threshold of the vasomotor center is about twice that of the flexion reflex and about four times that of the nerve-muscle preparation of the spinal cat. This may possibly be taken as further evidence of the effect of the interpellation of synapses on such tests.

At this time the work was carried over to an examination of psychopathic human subjects. In a preliminary survey ${ }^{17}$ it was found that the threshold of the psychopathic patient tends to be high, the average

13. Martin, E. G.; Paul, B. D., and Welles, E. S.: A Comparison of Reflex Thresholds with Sensory Thresholds. The Relation of This Comparison to the Problem of Attention, Am. J. Physiol. 26:428, 1915.

14. Porter, E. L.: Thresholds of Electric Stimulation in the Spinal Cat Determined by the Martin Method, Am. J. Physiol. 31:141, 1912.

15. Porter, E. L.: Variations in Irritability of the Reflex Arc. I. Variations Under Asphyxial Conditions, with Blood Gas Determinations, Am. J. Physiol. 31:223, 1913.

16. Martin, E. G., and Lacey, W. H.: Vasomotor Reflexes from Threshold Stimulation, Am. J. Physiol. 33:212, 1914. Martin, E. G., and Stiles, P. G.: Two Types of Reflex Fall of Blood Pressure, ibid. 34:106, 1914; ibid.: The Influence of Curare on Vasomotor Reflex Thresholds, ibid. 34:220, 1914; ibid.: Some Characteristics of Vasomotor Reflexes, ibid. 37:94, 1915.

17. Grabfield, G. P.: Variations in the Sensory Threshold for Faradic Stimulation in Psychopathic Subjects: First Note, Boston M. \& S. J. 161: $883,1914$. 
value in this group of cases being 223 beta units as against 100 beta units in the normal person. It was further shown that this test was a feasible one for routine use in psychopathic subjects.

The larger psychiatric entities were then studied. In the manicdepressive group ${ }^{18}$ it was found that the maniacal patients had a normal or slightly lowered threshold, and that the depressed patients showed a faradic hypesthesia which wore off as the depression disappeared. It was felt that this variation in the threshold was probably intimately connected with the fundamental cause of the variations in emotional tone in these cases. Kraepelin ${ }^{19}$ believes that this disease is caused by a congenital predisposition to mania or depression, as the case may be, and that the alternating forms may be found either in the manic or the depressive temperament as a basis. He further believes that this predisposition is manifested in the personality of the person when he is normal. He uses the fact that maniacal attacks may be superposed on the depressive temperament as an argument for his contention that mania and depression are different degrees of the same process and not opposites as would appear. The threshold for touch, temperature and pain has been found to be high in depressed patients as measured by tests of relative accuracy. The association time in manic cases is somewhat lengthened, but is more so in depressed cases. Southard ${ }^{20}$ has shown that there is an absence of gross brain lesions in the brains of manic-depressive subjects, and his findings and that of others have indicated the functional character of this disease. This same observer has noted lesions of the thalamus in cases ${ }^{21}$ other than manic depressive insanity, that showed during life hyperkinesis and its psychical accompaniments. Similarly, Bevan Lewis ${ }^{22}$ has described an absence of metabolic pigment in hyperkinetic states, and Southard and Bond ${ }^{23}$ have shown that there is an increase of metabolic or catabolic lipoid substances in the cortex of depressed cases of manic depressive insanity. From the work on the thalamus it was suggested

18. Grabfield, G. P.: Variations in the Sensory Threshold for Faradic Stimulation in Psychopathic Subjects: II, Manic Depressive Insanity, Boston M. \& S. J. $173: 148,1915$.

19. Kraepelin, E.: Psychiatrie, Ed. 8, Leipzig, 1913.

20. Southard, E. E.: Anatomical Findings in the Brains of Manic Depressive Subjects, Proc. Am. Psychol. Assn., May, 1914.

21. Southard, E. E.: The Association of Various Hyperkinetic Symptoms with Lesions of the Optic Thalamus, J. Nerv. \& Ment. Dis. 41:617, 1914.

22. Lewis, W. Bevan: A Textbook of Mental Diseases, Philadelphia, P. Blakiston's Son \& Co., 1890.

23. Southard, E. E., and Bond, E. D.: Clinical and Anatomical Analysis of Eleven Cases of Mental Disease in the Second Decade, with Special Reference to a Certain Type of Cortical Hyperpigmentation in Manic Depressive Insanity, Am J. Insan. 71:194, 1914-1915. 
that the hyperkinetic states might be associated with a withdrawal of the corticothalamic "inhibitory" or "switch-setting" impulses, that is, with a "tissue simplification." It is possible from the histopathologic evidence in the opposite state that these depressions may be associated with an accumulation of catabolic products. In view of this evidence and the reactions we have demonstrated in the receptor mechanism, it was suggested as a working hypothesis that these two contrasted states in this psychosis might be brought about by a functional hypertonicity or hypotonicity (for depression and mania, respectively) of these or similar centers. This hypothesis is further supported by Sachs' ${ }^{24}$ demonstration of the intimate relation between the thalamus and sensation. Additional suggestive evidence as to possible variations in the reactions of such centers is the demonstration that with threshold stimulation of a peripheral nerve the reflex vasomotor center ${ }^{25}$ responds with a depressor effect, while with markedly supraliminal stimulation it responds with a pressor effect. ${ }^{26}$

In the dementia praecox group, on the contrary, no such variation with emotional tone is observable in the faradic threshold, ${ }^{27}$ and it was concluded from this that the phenomenon of emotional tone in this group was probably governed by a different mechanism than in the manic-depressive syndrome. In the diagnosis of these cases we have largely followed Kraepelin, i. e., cases ending in deep dementia and displaying as their chief symptoms basic disorders in the personality, progressive deterioration and absence of the tendency to recover. There was found a close parallelism between cases showing symptoms of catatonia (silliness, grimacing, attitudinizing, stupor, cerea flexibilitas, negativism, etc.) and high threshold values, and between low threshold values and absence of such symptoms. These symptoms have been correlated with postrolandic lesions in these cases by Southard, ${ }^{28}$ and this finding suggests the postcentral cortex as the "arrivalplatform" of faradic sensation. Similarly, patients with somatic delu-

24. Sachs, Ernest: On the Structure and Functional Relations of the Optic Thalamus, Brain 32:95, 1909.

25. Porter, W. T.: The Vasotonic and the Vasoreflex Center, Am. J. Physiol. 36: $418,1915$.

26. Porter, W. T.: The Relation of Afferent Impulses to the Vasomotor Center, Am. J. Physiol. 27:276, 1910.

27. Grabfield, G. P.: Variations in the Sensory Threshold for Faradic Stimulation in Psychopathic Subjects: III, The Dementia Praecox Group, Boston M. \& S. J. 173:202, 1915.

28. Southard, E. E.: A Study of the Dementia Praecox Group in the Light of Certain Cases Showing Anomalies or Scleroses in Particular Brain Regions, Proc. Am. Medico-Psychological Assn., May, 1910; ibid.: On the Topographical Distribution of Cortex Lesions and Anomalies in Dementia Praecox with Some Account of Their Functional Significance, Am. J. Insan. 71:382, 1914-1915. 
sions have shown higher threshold values than patients not exhibiting such delusions. This lends support to the hypothesis that these delusions are often a result of disturbances in the receptor mechanism, although they may have their basis in fact, as shown by the lesions found at necropsy in the organs about which the delusions occurred in life. $^{2 \theta}$ Thus from this group there has been obtained evidence to show that the arrival platforms for faradic sensation are probably located in the postcentral gyrus with other forms of peripheral sensibility.

The alcoholic group has yielded little information for present purposes, though perhaps the most important from a clinical point of view. It was found ${ }^{30}$ that the chronic alcoholic invariably had a high threshold for this form of stimulation, and that this threshold fell after the withdrawal of the drug. In most of these cases (except those of Korsakow's psychosis and a few others) neuritis was not demonstrable by ordinary clinical methods or histologically in those that came to necropsy. It has thus been possible to demonstrate a distinct functional impairment in the receptor mechanism, by this method, without evidence of structural lesion. Apparently such a change in function can be induced by the administration of drugs to normal subjects, human or animal. E. L. Porter ${ }^{31}$ has demonstrated increase in reflex irritability after the administration of strychnin to the experimental animal. Martin, Grace and McGuire ${ }^{32}$ have shown a rise in this threshold in normal human subjects after the ingestion of moderate doses of acetphenetidin, and Dodge and Benedict ${ }^{33}$ have shown a similar rise after varying doses of alcohol. The results obtained in the cases of Korsakow's syndrome showed that a severe, frank neuritis can exist without total impairment of conduction power, although these cases showed the highest values in this group, as was to be expected.

The psychoneuroses, ${ }^{34}$ with the exception of the occupation neuroses and the traumatic neuroses, show a normal esthesia to faradism. In

29. Southard, E. E.: On the Somatic Sources of Somatic Delusions, J. Abnorm. Psychol. 7:326, 1912-1913; ibid.: The Possible Correlation Between Delusions and Cortex Lesions in General Paresis, ibid. 8:259, 1913-1914.

30. Grabfield, G. P.: Variations in the Sensory Threshold for Faradic Stimulation in Psychopathic Subjects: IV, The Alcoholic Group, J. Nerv. \& Ment. Dis. 45:410, 1917.

31. Porter, E. L.: Variations in Irritability of the Reflex Arc. II. Variations Under Strychnin, Am. J. Physiol. 36:171, 1915.

32. Martin, E. G.; Grace, C. M., and McGuire, J. H.: The Influence of Drugs on the Human Sensory Threshold, J. Pharmacol. \& Exper. Therap. $6: 257,1915$.

33. Dodge, R., and Benedict, F. G.: Psychological Effects of Alcohol, Publication No. 232, Carnegie Institution of Washington, Washington, D. C., 1915.

34. Grabfield, G. P.: Variations in the Sensory Threshold for Faradic Stimulation in Psychopathic Subjects: V, The Group of Psychoneuroses, J. Abnorm. Psychol. 11:328, 1916-1917. 
such cases no structural pathology has ever been demonstrated. The occupation and traumatic neuroses are, sometimes at least, associated with demonstrable lesions. However, the results in the few cases of occupation neuroses that opportunity has permitted us to examine, seems to point to a possible division of these cases into those in which there is a true neuropathy or "functional neuropathy," 3 " and those of a purely psychogenetic nature. As to the traumatic neuroses, we have only seen two cases, both of which yielded definitely pathologic values by this test. We felt that these cases probably had an organic basis, even though they were quite negative to usual clinical methods of examination. The results in this group emphasize the possibility of obtaining, by this method, evidence of true functional impairment impossible of demonstration otherwise. Clinically, the results of this test are of importance in aiding in the differentiation of these cases from the true psychoses.

The epileptics, senile and syphilitic cases have not been considered, and will be taken up later together with the data derived from other cases showing definite neurologic lesions.

DATA

Data for the present study were obtained from 612 observations on 261 cases chosen at random from the admissions to the Psychopathic Hospital, Boston. Patients obviously unsuitable were not attempted.

In this group of cases (see Table 1), as in the first group studied, it is seen that the threshold of the psychopathic patient tends to be high, the value in the entire series averaging 197 beta units. This tendency of the psychopathic patient to have a faradic hypesthesia is not due to his mental incapacity as such. The only results here reported are those in which there was no doubt as to the validity of the reading, i. e., those in which conscious or unconscious deception on the part of the patient tested could be absolutely ruled out.

The Peripheral Neuron.-Cases such as those showing frank neuritides invariably yielded high threshold values. This is true whether there was in addition to the peripheral lesion a central lesion or not. As an example of the former are the cases presenting Korsakow's syndrome, and of the latter, cases of alcoholic neuritis without demonstrable central lesions.

As has been pointed out above, in many cases this method shows an hypesthesia in cases where such an impairment has not before been suspected. In the four cases of acroparesthesia studied (these are classified with the neurologic group in Table 1), we found uniformly

35. Southard, E. E., and Solomon, H. C.: Occupation Neuroses, in Handbook for Occupational Diseases, Ed. by Hanson, Washington, D. C. 
high threshold values, confirming the suspicion from previous studies that the peripheral receptor system was impaired in this disease. Oppenheim ${ }^{36}$ considers that this may possibly be a spinal cord condition, but that "it is probably due to a condition of irritation in the vasomotor centers, by which the arteries are contracted and the nutrition of the sensory nerve endings in the extremities are impaired. The same author also describes these cases as being negative to sensory tests or showing "merely slight decrease of the sensibility of the finger tips."

Table 1.-Data Avallable in 261 Cases Studied*

\begin{tabular}{|c|c|c|c|c|}
\hline Diagnosis & $\begin{array}{l}\text { Number } \\
\text { Studied }\end{array}$ & $\begin{array}{l}\text { Number of } \\
\text { Observa- } \\
\text { tions }\end{array}$ & $\begin{array}{l}\text { Limits of } \\
\text { Variation in } \\
\text { Beta Units }\end{array}$ & Average \\
\hline 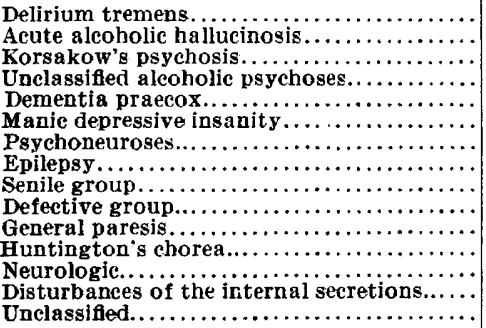 & $\begin{array}{r}22 \\
16 \\
6 \\
14 \\
51 \\
25 \\
30 \\
8 \\
7 \\
12 \\
18 \\
2 \\
20 \\
4 \\
26\end{array}$ & $\begin{array}{r}32 \\
25 \\
18 \\
20 \\
87 \\
66 \\
113 \\
12 \\
11 \\
22 \\
50 \\
4 \\
104 \\
6 \\
42\end{array}$ & $\begin{array}{r}85-493 \\
46-545 \\
156-1560 \\
86-600 \\
61-777 \\
23-1661 \\
41-785 \\
108-408 \\
124-738 \\
65-364 \\
41-589 \\
141-650 \\
38-1881 \\
115-234 \\
66-621\end{array}$ & $\begin{array}{l}241 \\
269 \\
443 \\
249 \\
186 \\
237 \\
179 \\
217 \\
274 \\
179 \\
271 \\
307 \\
292 \\
147 \\
210\end{array}$ \\
\hline Total. & 261 & 612 & $23-1881$ & 197 \\
\hline
\end{tabular}

* The averages in the table are without any corrections for wrong diagnoses or complicating conditions, such as alcoholism, which would tend to raise or lower the threshold, thus throwing such a case out of alignment with jts group.

From the study of this group we may safely conclude that lesions of the peripheral neuron cause a faradic hypesthesia, though we have not yet encountered clinically a faradic anesthesia from such a lesion, no matter how severe.

The Spinal Neuron. - Cases showing lesions of the posterior columns have for the most part high threshold values. We have examined five cases of this type: two of tabes dorsalis, two of taboparesis and one of ataxic paraplegia. Case No. $4656^{37}$ showed clinically an hypesthesia over the ulnar distribution of both hands and a hyperalgesia over both arms. The grip of the right hand was stronger than that of the left. Using the little and ring fingers the threshold value on the left was 326 and on the right 574 beta units; using the index and middle fingers (these were the ones used throughout this work unless otherwise stated) the threshold on the left was 159 , and

36. Oppenheim, H.: A Textbook of Nervous Diseases, Ed. 5, 1911. Trans. by Alexander Bruce, New York, 1911.

37. Case numbers refer to the record numbers in the Psychopathic Hospital, Boston. 
on the right 383 beta units. Thus it is seen that in this case the diminution in sensory acuity on the ulnar side is accompanied by a diminution in faradic sensibility. The values are higher on the side of the body showing the greater muscular power in this case. Case No. 3931, diagnosed as taboparesis, showed diminution of sensibility to pain over the legs and chest, but no sensory changes over the arms. This case showed a threshold of 433 beta units. However, the cortical involvement in this case must be borne in mind. The case of ataxic paraplegia studied showed a threshold of 178 on the right and 143 on the left. Cutaneous sensation was clinically unimpaired. The reflexes were greater on the left than on the right, but it was noted that this is a doubtful finding. The case seems to make negative the effect of posterior column sclerosis, per se, in raising this threshold. The lesions in the spinal ganglion in tabes may well be the chief cause of the raised threshold in these cases, assuming that such lesions most probably affect more than the fibers of deep sensibility.

TABLE 2.-Figures in Beta Units Obtained from Examination of All the Fingers in Pairs of a Case Showing Residua from an Attack of Botulism

\begin{tabular}{|c|c|c|}
\hline Fingers Used & Right & Left \\
\hline 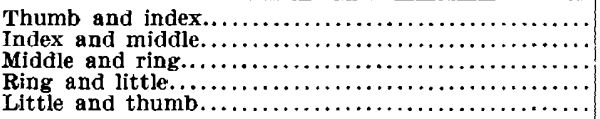 & $\begin{array}{l}282 \\
293 \\
252 \\
255 \\
361\end{array}$ & $\begin{array}{l}127 \\
128 \\
163 \\
217 \\
214\end{array}$ \\
\hline 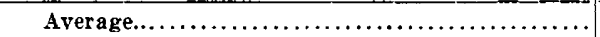 & 289 & 170 \\
\hline
\end{tabular}

Further evidence as to the spinal path is obtained from the study of a case showing certain residua following an attack of botulism. The case has been reported ${ }^{38}$ elsewhere. At present this patient has a hemithermo-anesthesia on the right including the entire body up to the ramus of the jaw, above which sensation is normal. On this side there is also a slight hyperalgesia and a slight hyperhidrosis. Extremes of heat and cold are felt as pain. On the left the threshold of all the fingers taken in pairs (see Table 2) averaged 170 beta units and showed an increasing hypesthesia as the ulnar side was approached. The right hand, on the contrary, similarly tested averaged 289 beta units, the lowest value obtained on this hand being 35 beta units above the highest on the left. This patient was not only not psychopathic but was trained in introspective observation. Subjectively he made the interesting

38. Stiles, P. G.: A Case of Apparent Food-Poisoning of the Type Known as Botulism or Allantiasis, J. A. M. A. $41: 2301$ (Dec. 27) 1913. 
observation that on the left the sensation was localized in the ends of the fingers, whereas on the right it was located between the two fingers tested and felt more like a muscle twitch.

Cases of Syringomyelia.-The results of two cases of syringomyelia tested in various ways properly fall in this section.

CASE 4166.--P. W., aged 40, had no mental symptoms except irritability of temperament. Blood pressure was: systolic 115, diastolic 75 . The Wassermann tests of blood and spinal fluid were negative. The pupils showed a slight horizontal nystagmus, especially the left. They reacted normally to light and accommodation. Biceps and triceps reflexes were absent. The abdominal reflex was absent. The Babinski and Oppenheim signs and ankle clonus were present on both sides. There was patellar clonus on the right. Knee jerks and ankle jerks were equal and exaggerated on both sides. The cremasteric reflex was absent. There was slight swaying in Romberg's position. Tactile sensation (light touch) was everywhere unimpaired. Temperature and pain sensation were lost everywhere except over the face. Ordinary clinical laboratory tests were essentially negative.

CASE 3729.-K. M., aged 54. The only mental symptoms that this patient showed were some persecutory delusions. Blood pressure was: systolic 170, diastolic 110. The Wassermann tests of the blood and spinal fluid were negative. There was marked tremor of the extended hands; marked scoliosis with convexity to the right-a true rotolateral curvature. Pupillary reactions were normal. The conjunctival reflex was absent. Biceps and triceps reflexes were absent. The abdominal reflex was absent. The knee jerks and ankle jerks were hyperactive but equal. Babinski's sign was absent. Oppenheim's sign was inconstant. There was ankle clonus on both sides, better sustained on the right. Romberg's sign was absent. Tactile sensation (light touch with cotton) was everywhere unimpaired. On the right side, however, she was unable to distinguish the head from the point of a pin. There was temperature anesthesia over the right arm and hand, and an apparent slight disturbance everywhere on both sides. Pain sense was absent on the right side and somewhat disturbed on the left. Deep sensation was well preserved everywhere. Muscle sense was poor. There was slight dysdiadokokinesia on the right. Ordinary clinical laboratory tests were essentially negative.

A number of observations (see Table 3 ) on both these cases show that Case 4166 had an average threshold on the right of 396 beta units as compared with 505 beta units on the left. Case 3729 averaged 928 beta units on the right and 472 on the left; the latter showed comparable figures in one observation made on the feet. It is interesting to note that both of these patients could distinguish painful faradic stimuli from threshold stimulation. These were roughly estimated on Case 3729 in the feet and were found to be 875 beta units on the left and 4,000 on the right. As a comparison, it is to be noted that the strength of stimulus at the threshold for these cases is, when applied to a normal person, distinctly painful. 
Cases of Cortical Lesions.-In this section we will consider those patients whose lesions are practically wholly cortical with evidence of a definite preponderance of damage on the one side or the other. In the cases of general paresis (see Table 4) there was no sensory impairment demonstrable by the usual clinical methods. It will be seen from the table that the more affected side averages 333 beta units as compared with 175 on the less affected side. In every case the threshold of the more affected side is higher than on the less affected side. Case P. B. has the following history:

Table 3.-Observations on Two Cases of Syringomyelia. No. 3729 Had Clinical Evidence of Advancement of the Process in the

Period of Observation

\begin{tabular}{|c|c|c|c|c|}
\hline Case Number & Parts Tested & Right & Left - & Date \\
\hline $\begin{array}{l}3729 \\
3729 \\
3729 \\
3729 \\
3729 \\
3279 \\
3729 \\
3279 \\
\mathbf{3 7 2 9} \\
\mathbf{3 7 2 9}\end{array}$ & 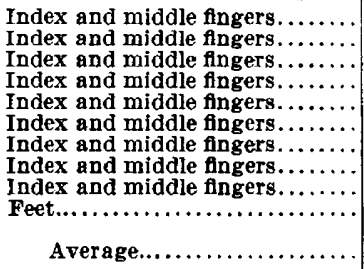 & $\begin{array}{r}845 \\
513 \\
766 \\
794 \\
345 \\
109 \\
1590 \\
692 \\
1881 \\
989 \\
928\end{array}$ & $\begin{array}{r}517 \\
131 \\
265 \\
333 \\
195 \\
246 \\
585 \\
679 \\
1302 \\
585 \\
472\end{array}$ & $\begin{array}{r}10 / 28 / 14 \\
11 / 2 / 14 \\
11 / 9 / 14 \\
11 / 17 / 14 \\
11 / 30 / 14 \\
12 / 6 / 14 \\
12 / 10 / 14 \\
1 / 2 / 15 \\
1 / 3 / 15 \\
12 / 10 / 14\end{array}$ \\
\hline $\begin{array}{l}4166 \\
4166 \\
4166 \\
4166 \\
4166\end{array}$ & 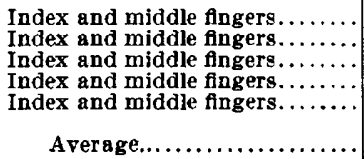 & $\begin{array}{l}302 \\
462 \\
418 \\
379 \\
418 \\
396\end{array}$ & $\begin{array}{l}560 \\
829 \\
307 \\
335 \\
444 \\
505\end{array}$ & $\begin{array}{l}1 / 11 / 15 \\
1 / 12 / 15 \\
1 / 14 / 15 \\
1 / 16 / 15 \\
1 / 17 / 15\end{array}$ \\
\hline
\end{tabular}

TABLE 4.-Cases of Cortical. Lesions

\begin{tabular}{|c|c|c|c|c|}
\hline Case Number & Diagnosis & $\begin{array}{c}\text { Threshold } \\
\text { Right }\end{array}$ & $\begin{array}{c}\text { In Betas } \\
\text { Left }\end{array}$ & $\begin{array}{c}\text { Side More } \\
\text { Affected }\end{array}$ \\
\hline $\begin{array}{l}3920 \\
3699 \\
3822 \\
3832 \\
3674 \\
3857 \\
\text { P. B. }\end{array}$ & 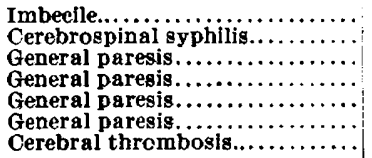 & $\begin{array}{l}119{ }_{270}^{105} \\
271 \\
182 \\
370 \\
400^{275} 843\end{array}$ & $\begin{array}{l}172{ }_{189}^{120} \\
196 \\
255 \\
260 \\
150^{215} 158\end{array}$ & $\begin{array}{l}\text { Left } \\
\text { Right } \\
\text { Right } \\
\text { Left } \\
\text { Right } \\
\text { Right } \\
\text { Right }\end{array}$ \\
\hline
\end{tabular}

He was a man of 50 , who in the early part of 1912 developed a spastic paralysis of the right side. A tumor in the left motor area was suspected. He was operated on and at operation a large mass of obviously extraneous tissue was removed from the left cortex. The process, it was seen, had also involved the postcentral gyrus. On pathologic examination it was found that this mass was composed of scar tissue, and it was decided that the process was in all probability an extensive cerebral thrombosis, apparently quite sharply localized to the left side. He made an excellent operative recovery, and went home in July, 1912. In December, 1914, he noticed a slight increase in the symptoms on the right. The left side gave him no trouble throughout the period that he was under observation. 
This patient, when first tested in 1912, showed a threshold of 150 beta units in the left hand and 400 in the right. In 1914, on his return, he showed a threshold of 158 beta units on the left and 843 on the right. In addition to the above, a number of patients have been tested who showed diffuse cortical lesions. These showed invariably a high threshold value and include the senile group, huntington's chorea, various syphilitic lesions including other cases of general paresis than those mentioned above (see Table 1). These cases will be discussed later.

\section{DISCUSSION}

It was to be expected that it could be shown that faradic stimuli used one of the paths described by Head, Rivers and Sherren. ${ }^{39}$ An absolutely dogmatic statement as to the path of these impulses is not warranted by the evidence now at hand, and further work should be done to firmly establish such a path.

Several hypotheses suggest themselves. Faradic stimuli may use all paths equally and therefore the impairment of any sensory path may raise the threshold value to this form of stimulation. However, there are serious objections to this in that the hypesthesia caused by lesions of pain and temperature fibers far exceeds that in which only other systems are involved. This suggests the hypothesis that such fibers are the path normally used by these stimuli. However, the finding of some sensory impairment in many cases considered chiefly motor would suggest the possibility of the path associated with the motor nerves, i. e., the fibers conveying deep sensibility. Such an hypothesis is supported by the findings in cases of peripheral neuritis showing almost wholly motor symptoms, such as contractures, paralyses, etc. Another implication is found in the cases showing posterior column sclerosis which invariably showed an hypesthesia.

Our feeling is that the degree of hypesthesia associated with lesions affecting the thermal fibers, as shown in the cases with dissociation of sensation, is so marked as compared with that caused by apparently equal destruction of other sets of fibers that we are justified in concluding that faradic sensibility is carried largely, if not wholly, by these fibers in the lateral columns. ${ }^{40}$ The hypesthesia found associated

39. Head, H.; Rivers, W. H. R., and Sherren, J.: The Afferent Nervous System from a New Aspect, Brain, 28:99, 1905. Head, H., and Sherren, J.: The Consequences of Injury to the Peripheral Nerves in Man, Ibid., p. 16. Head, H., and Holmes, G.: Sensory Disturbances from Cerebral Lesions, Ibid., 34:102, 1911-1912. Rivers, W. H. R. ,and Head, H.: A Human Experiment in Nerve Division, Ibid. 31:323, 1908.

40. Head, H., and Thompson, T.: The Grouping of Afferent Impulses in the Spinal Cord, Brain 29:537, 1906. May, W. Page: The Afferent Path, Ibid., p. 742. 
with other spinal lesions can be explained by the statement that these fibers may be affected without clinical evidence and that the delicacy of this reaction has discovered hitherto unsuspected involvement. This is not too great an assumption in view of the fact that impairment of sensation has been demonstrated by this method in patients thought to have normal sensibility. We cannot exclude the other fibers as a path in stimuli of great intensity, as there may be a spread or a change in reaction - each of which possibilities has analogues in the behavior of the nervous system. We have not mentioned the possibility of a separate set of fibers carrying this sensation as the teleological argument against such fibers is practically conclusive. We believe, therefore, that the evidence points strongly to the thermal fibers as the path of this form of stimulation.

Presumably, then, we should find evidence that the postcentral convolution is the arrival platform for the impulses that we are studying. The evidence on this point, while mostly indirect, is, we believe, conclusive. That this gyrus contains the sensory projection areas was shown experimentally by Cushing ${ }^{41}$ (see also Bergmark ${ }^{42}$ ). We have derived evidence on this point from a study of a large variety of cases showing various cortical pathology, some diffuse and some localized. Those cases showing widespread general cortical pathology invariably showed high threshold values.

The cases of epilepsy studied (see Table 1) showed an average threshold of 217 beta units - a marked disturbance of the receptor mechanism for this form of stimulation which cannot be accounted for by peripheral lesions. Unfortunately, the evidence of cortical pathology is not conclusive. Southard has studied the glia tissue in epilepsy, ${ }^{43}$ and he suggests that the epileptic dischargè really depends on the simplification of the course of the sensorimotor afferent impulses by a reversion of this synapse to the spinal type. This may be correlated with our results in so far as they indicate the possibility of increased synaptic resistance between afferent impulses and the paths leading to the nonmotor areas of the cortex, and thus imply the possibility of lowered synaptic resistance to impulses from the periphery to the motor cortex. The few normal values obtained in this group may be correlated with the possible true idiopathic epilepsy. ${ }^{44}$ However, while most

41. Cushing, H.: A Note on the Faradic Stimulation of the Post cerebral Gyrus in Conscious Patients, Brain 32:44, 1909.

42. Bergmark, G.: Cerebral Monoplegia with Special Reference to Sensation and to Spastic Phenomena, Brain 32:342, 1909.

43. Southard, E. E.: On the Mechanism of Gliosis in Acquired Epilepsy, Am. J. Insan. 64:607, 1908.

44. Thom, D. A., and Southard, E. E.: An Anatomical Search for Idiopathic Epilepsy, Rev. Neurol. \& Psychiat. 13:471, 1915. 
of the research up to the present has been unsatisfactory, ${ }^{45}$ the cause of this condition is likely to be found in the abnormal excitability of the efferent path. If this proves to be true, an efficient reaction of the organism would be a decreased excitability of the afferent path or an increase in the resistance of the synapses between the two in the cortex. It seems not unlikely that the faradic hypesthesia here demonstrated represents the effects of some such protective reaction.

In the senile group of psychoses high values have been found. These cases are usually associated with gross brain lesions at necropsy. In previous work, however, we have gained the impression that there is a decreasing sensitivity with increasing age (though not to what we have considered pathologic values). Such an hypesthesia as this may be accounted for by impaired nutrition of nervous tissue either in the periphery or centrally either due to frank arteriosclerosis or to the "narrowing of the capillary field" which Mackenzie ${ }^{46}$ has pointed out.

Another small group of cases in which there is generalized cerebral involvement is that of Huntington's chorea. Oppenheim ${ }^{36}$ states that there are "disseminated, miliary, encephalitic foci especially in the cortex and the motor region," and Spiller ${ }^{47}$ noted a proliferation of the neuroglia, especially in the second and third layers of the cortex chiefly in the motor area. He also conveys the impression that this is a diffuse process. These cases showed a constantly high threshold, and with such cerebral findings at necropsy the possible relation of the effect of lesions of what are probably associational regions on sensation, seems worth further study.

In respect to general cerebral conditions, we have had the opportunity of examining two cases in which the clinical signs were only of increased intracranial pressure. Both these cases showed a high threshold value on both sides without preponderance of hypesthesia on the one side or other. The one proved to have a left cerebellar tumor and the other a large glioma occupying chiefly the midbrain.

From the foregoing paragraphs it is seen that general lesions of the cortex and various changes of the relations inside the cranium apparently cause an hypesthesia. The cases mentioned which showed a preponderance of lesion on one side or the other and a corresponding preponderance of hypesthesia complete the evidence that the postcentral cortex is the arrival platform for these impulses. In addition, there is

45. Vogt, H.: Epilepsie, in Handbuch der Psychiatrie, Spezieller Teil 1ste Abteilung, Ed. by G. Aschaffenberg, 1915.

46. Mackenzie, James: Diseases of the Heart, Ed. 3, London, 1914.

47. Spiller, W. G.: Symptomatology, Pathology and Treatment of Choreiform Movements, J. A. M. A. 44:433, 1905. 
evidence concerning this in the study of the dementia praecox group which brings out a striking parallelism between the postrolandic lesions discovered in catatonic cases by systematic brain photography ${ }^{48}$ and high threshold values.

We have, then, evidence that threshold faradic sensation is carried by the peripheral neuron following the path of the thermal fibers in the cord and arriving at the cortex in the postcentral gyrus. Lesions of any portion of this path produce an hypesthesia to faradic stimulation.

In conclusion, we wish to emphasize the possibilities of further study of the nervous system by this method, both experimentally and clinically, as a means of throwing some light on the variations in the reactions of the nervous system under various physiologic and pathologic conditions, the latter whether structural or functional.

\section{SUMMARY AND CONCLUSIONS}

1. The method of Martin for determining the strength of shocks delivered by the secondary coil of an inductorium in absolute units is described as used by us in the determination of the sensory threshold for faradic stimulation in 261 cases (612 observations). The advantages of this method over previous methods is pointed out.

2. Previous work with this method is reviewed.

3. Clinical considerations have been purposely omitted from this discussion, but it is to be noted that the epileptic, senile and syphilitic groups of cases tend to have a faradic hypesthesia. These groups have not been reported elsewhere.

4. Cases of acroparesthesia and Huntington's chorea, though few in number, showed constantly a pathologically elevated sensory threshold value in beta units, i. e., the number of units of shock required to cause sensation.

5. Certain suggestions as to the mechanism of the relation of the variation of sensibility with that of emotional tone in the cases of manic-depressive insanity have been made.

6. From a study of this pathologic material, the hypothesis is suggested that faradic stimuli use the path of the thermal fibers in the cord and presumably in the peripheral nerves, arriving in the cortex at the postcentral gyrus. Lesions affecting any part of this path either

48. Southard, E. E.: On the Direction of Research as to Analysis of Cortical Stigmata and Focal Lesions in Certain Psychoses, Trans. Assn. Am. Physicians 29: 1914. 
functionally or structurally cause an hypesthesia to this form of stimulation. It was impossible to determine whether such stimulation used the thermal receptors in the skin.

It is a pleasure to acknowledge my indebtedness to Dr. E. G. Martin for his help and to Drs. H. A. Christian, H. Cushing, W. E. Paul, and E. W. Taylor for the privilege of examining certain cases reported here.

In conclusion I wish to express my sincerest thanks to the late Dr. E. E. Southard, not only for placing the clinical material at my disposal, but also for his kindly interest and invaluable and stimulating suggestions throughout this work.

University Hospital. 